\title{
The pharmaceutical company
}

\author{
R. G. HoARE \\ F.P.S. \\ Imperial Chemical Industries Limited
}

\begin{abstract}
Summary
Trade name prescribing benefits the Pharmaceutical Industry by providing income to support research and development of drugs, and is essential to protect a company during the patent life of a product.
\end{abstract}

LET me begin by saying that the Industry believes that brand names serve a useful purpose, not only for the manufacturer himself but also for the prescriber and ultimately his patient. The brand name provides a unique identification of the complete medicine, its quality and source of manufacture, and in our view its use represents the simplest way for a prescriber to ensure that his patient receives exactly that which is intended for him. I need hardly emphasize the growing importance we attach to-day to consistent and predictable quality and bio-availability, closely related to which is the need for precise identification, not only of the active entity, but also of the complete pharmaceutical preparation within which it is contained.

There are others here to-day, however, more qualified than I to discuss these aspects, and I will concentrate instead on the economic significance of brand names for the National Health Service and for pharmaceutical innovation in our industry. I will also comment briefly on the criticism that brand names cause confusion in prescribing.

Let me turn first to the economic significance of 'generic prescribing' to the National Health Service. It is certainly true that if doctors were to switch from prescribing a modern branded antibiotic to penicillin, or from a modern non-barbiturate hypnotic to phenobarbitone, or from a modern anti-depressant to amphetamine, then their prescribing costs would be dramatically reduced. Such a reduction, however, would arise not from a switch between brand and generic names, but from the substitution of less effective, more dangerous treatments for their safer and more effective modern counterparts. It is equally true, however, that these newer medicines will cost more than their predecessors.

When we consider, therefore, the savings potential for the NHS from the use of generic names, we are, in fact, talking about those cases where the same active ingredient is available from more than one manufacturer at different prices. A generic prescription in such cases enables the pharmacist to dispense the cheapest formulation which he can buy. These situations usually occur after the expiry of patents, allowing other manufacturers (who need do no research and very little development) to enter the market at a lower price. This, of course, is legitimate practice and is exactly the intention of the patents legislation, but the magnitude of the potential savings to the NHS under these circumstances depends upon two factors. The first is the extent to which the originator of the product has been able to reduce his prices during the patent life to meet the expected competition, and secondly the extent to which the product has already been superseded by other treatments. Savings will be significant only if, at patent expiry, the product is still widely prescribed and, I stress, still highly priced. The point to be made here, however, is that in practice, such a combination of circumstances is rare

Usually we find a different state of affairs; e.g. with imipramine, nitrofurantoin and phenylbutazone to quote three well known products. In such cases, extensive competition has occurred from cheaper brands, but the resultant savings to the NHS have been minimal since each had already been overtaken by new and presumably superior chemical compounds by the time their patents had expired.

I would like to repeat the point made by $\mathrm{Mr}$ Teeling-Smith in his opening talk, that the potential savings to the NHS will never represent more than a very few per cent of the total pharmaceuticals cost, which in itself has stayed constant at around $10 \%$ of the total cost of the NHS since the very inception of the Service 25 years ago. It is to perpetuate a myth to allege that generic prescribing would save the NHS tens of millions of pounds a year.

You may well ask why the Industry is so concerned to preserve brand names when apparently the specific use of brand names adds only a very small percentage to the total value of sales to the Health Service.

There are two answers to this question. The first is that although relatively small sums of money are 
involved in NHS terms, the sums become very substantial to the originators of the products whose patents have expired. The continued income from sales of the original brand serves to shelter the originator from an otherwise catastrophic fall in earnings, even though the market for the product and his share of that market may be declining. It provides continued support for the research costs between major breakthroughs, and provides a few years of grace to adjust to the economic effectsto quote one specific example-of falling from number 2 to number 22 in the sales league in a period of only 2 years or so.

The second and more general answer to the question is that the Industry is dependent upon brand names to protect the industrial property they represent. Like patents, brand names are considered, certainly by the research-based sector of our Industry, to be one of the key factors determining the effort they are prepared to devote to the scientifically complex and economically risky business of drug innovation. Non research-based companies will always be able to sell at lower prices. In the absence of brand names, such marginally cheaper copies would invariably be dispensed, to the ultimate detriment of further progress.

The Sainsbury Committee recommended that brand name prescribing be replaced by the use of the generic name, coupled with that of the manufacturer. For the first 10 years or so of its life, a drug is available only from its originator and doctors would soon realize the timewasting involved in writing out two names instead of one, the manufacturer's name would be omitted, and it seems inconceivable that the doctor could then be persuaded to add back this vital feature when the patent had expired. In practice, the effect of the Sainsbury recommendation would be no different from the total abolition of brand names.

The British Pharmaceutical Industry earns for this country a substantial balance of payments surplus; record exports of $£ 180 \mathrm{~m}$ were earned last year. Most of the countries to whom we sell still rely on brand names in prescribing and it would be damaging to the Industry if it were forced to avoid brand names in its home market.

This brings me to the criticism that the use of brand names can promote confusion among prescribers by concealing the pharmacological nature of the treatment. We are all familiar with the party tricks of those who put up the names of a dozen or

so similar preparations on a blackboard and then $\stackrel{\mathbb{Q}}{\varrho}$ defy any general practitioner in the room to classify $c$. them all into their correct pharmacological groups. $\vec{F}$ Similarly, we have all heard the story of the doctor $\stackrel{5}{?}$ who switched his patient from one unsuccessful ? brand of antibiotic to another containing the $\frac{\bar{\sigma}}{\bar{c}}$ identical active ingredient, but just how representa- $\frac{N}{\sigma}$ tive are such cases? Indeed, one of the points about $\varnothing$ branded products is that they give some assurance $\infty$ of quality and consistency - the doctor only able to $\overrightarrow{0}$ prescribe generically may indeed be justified in questioning the antecedents of the formulation dispensed.

While I believe this talk of confusion to be exaggerated, let me say that I believe Industry has a responsibility to make its brand names reasonably of meaningful and wherever possible to avoid the risk in of confusion. I think we still need to give more $\stackrel{\infty}{\circ}$ attention to this, but I venture somewhat hesitantly o o to suggest that brand names cause less confusion in $ᄋ$ the practical realities of general practice than to those who strive for theoretical perfection in the teaching hospitals. The general practitioner, for example, 을 relies to a great extent in his everyday practice on what I might term the unglamorous remedies, which 2 often contain several active ingredients. I heक्की $\overrightarrow{0}$ nothing from those in favour of generic prescribins to simplify the problem of describing such produces simply and accurately, unless of course their search for perfection seeks also to abolish these stable remedies. To propose generic names for combinations raises many problems, not the least of which would be the need to devise a specific name for each and every quantitative mixture. But a perfectly good name already exists, i.e. the brand name! As I said at the beginning, the brand name provides a simple, unique identification of the complete medicine.

To conclude, I have tried briefly to put into perspective the economic significance of brand names for the Health Service and for the British Pharmaceutical Industry. In our view, their advantages far outweigh the disadvantages. I have been unable in the time allotted to emphasize the importance to the Industry and, I believe, to medicine and the nation at large, of taking a broad view of all the Industry's $\frac{7}{0}$ activities. To condemn brand names because they fall short of ethical perfection, while being ignorant $N$ of the part they play in the complex business of drug innovation, can do nothing but harm to an Industry which, on its record, has served the medical profession and population of this country very well.

\section{Discussion}

Dr Curzon, a general practitioner from South London, assumed cynically that the main reason pharmaceutical companies preferred brand name prescribing was that sales of their products were assured; this was acceptable if the bio-availability and therapeutic activity of the product was shown 
to be superior to other available products. In many instances, no such advantage has been shown. He suggested an independent review body, financed jointly by Government and industry, to provide reliable advice for practitioners on the equivalence of products. Mr Baker regretted that at present, sufficient data was not available to make comparisons for most products; he suggested that in most instances the margins of safety were wide, while bio-availability differences were small and therefore unlikely to be important.

Dr F. Hartley, Dean of the School of Pharmacy and Chairman of the British Pharmacopoeia Commission, argued that the question could not be settled in terms of black and white. On the one hand, the Pharmaceutical goose must be encouraged to continue to lay golden eggs; on the other hand, we must be aware of the possible financial savings which can be made. It should be remembered that even with a branded product, one cannot assume that there is no batch to batch variation. Prescribing by trade name does not guarantee that the product is the same on every occasion. Dr Hartley suggested that rather than another review body, a stimulus was required for a co-operative venture with the pharmaceutical industry towards producing more complete specifications for products. Only in this way would a constancy of therapeutic effect be achieved. This problem cannot be solved either by purely approved name prescribing in the pursuit of economy or purely trade name prescribing providing perpetual monopoly for the manufacturer.

Dr H. L. F. Currey suggested that the greatest economy in prescribing habits would be achieved by education of practitioners to avoid the present enormous problem of over-prescribing. He thought that the introduction of trade names presented a great barrier to communication and therefore to education. 